\title{
Research on the Phenomenon of Chinese Residents' Spiritual Contagion for the Reuse of Recycled Water Based on SC-IAT
}

\author{
Hanliang Fu * and Xiaojun Liu \\ School of Management, Xi'an University of Architecture and Technology, Xi'an 710055, China; xjun_liu@163.com \\ * Correspondence: fu_hanliang@yeah.net
}

Received: 28 September 2017; Accepted: 30 October 2017; Published: 2 November 2017

\begin{abstract}
Recycled water has been widely recognized in the world as an effective approach to relieve the issue of water shortage. Meanwhile, with several decades of development, the insufficiency of technology is no longer the primary factor that restricts the popularization of recycled water. What makes it difficult to promote the concept of reusing recycled water in China? To solve this issue, a special experiment on the public's attitude towards the reuse of recycled water was designed based on a Single Category Implicit Association Test (SC-IAT), so as to avoid factors like social preference that can influence the survey results, and to gain the public's negative implicit attitude towards reusing recycled water reuse, which is close to the public's real attitude to it. From the perspective of implicit attitude, this research testifies the "spiritual contagion" phenomenon of the public, which refers to refusing recycled water reuse because recycled water is made from sewage treatment. By comparing the implicit attitude to recycled water reuse with the explicit attitude that is acquired from self-reporting questionnaires about reusing recycled water, this research finds that the implicit attitude is more positive than the explicit attitude, which accounts for the phenomenon of "best game no one played" in the promotion of the recycled water reuse, that is, the public though applauding the environment-friendly policy, will not actually use the recycled water.
\end{abstract}

Keywords: recycled water reuse; spiritual contagion; single category implicit association test

\section{Introduction}

With the development of the economy, the increase of population and the improvement of people's life quality, water consumption and pollution have greatly increased, which even go beyond the limits of the Earth's carrying capacity, and result in irreversible damage to ecological systems [1]. The restrictions brought about by water resources and water environments' carrying capacity to the social and economic development have become an important issue that must be considered in the 21st century. Thus, the search for alternatives to natural water resources has since become a common task for mankind today. Recycled water supply is more stable than natural water resources that depend on precipitation. It not only can be used as a new source of water but also can help to reduce water pollution, so it becomes an important alternative to natural water resources [2,3]. Nowadays, sewage treatment technology has been developed to produce recycled water that can be used in many fields. However, in reality, the scale of recycled water reuse is still limited [4]. Why has sewage recycling technology, proven to be effective, not been implemented yet on a broad scale? As early as the end of last century, there were scholars who realized that the biggest obstacle to recycled water reuse promotion is not backward technology, but low acceptability (ACC) of the public. In purifying recycled water from sewage, any malfunction of the technology and human error may permit passage of some harmful microbiological and chemical residue [5]. Therefore, the public's concern about the health risk 
caused by recycled water is also an important reason for low ACC [6]. On this basis, Rozin et al. define the reason underlying the public not using recycled water to be "Spiritual Contagion" [7].

The present rapid urbanization process and the rapid development of the society and economy in China has been increasing the water pollution and enlarging the gap between water supply and demand, which makes the promotion of recycled water reuse be in great need. Nevertheless, in China, there is little research exploring the reasons for promotion difficulties of recycled water reuse through investigating the public's ACC of recycled water. At the same time, since recycled water is an environment friendly and publicly beneficial product, the public will probably hide their real attitude towards it for the sake of face-saving and maintaining reputation or following the status quo. They would possibly show as being more preferable to recycled water. Therefore, it is often difficult to learn about their real attitude toward recycled water. The Implicit Association Test (IAT), however, can overcome this difficulty. IAT is able to hide the purpose of the experiment from the participants by explicit experiment design, so that the experiment result (implicit attitude) will be closer to their real attitude.

\section{Research Methods and Hypotheses}

\subsection{Research Methods}

On the basis of many classic cases in the field of implicit social cognitive research, such as Stroop task, Greenwald et al. propose the implicit association test (IAT), which is also based on the response time paradigm in 1998. Implicit attitudes are actions that are under the control of automatic activated evaluation, without the performer's awareness, and the IAT procedure seeks to measure implicit attitudes by measuring their underlying automatic evaluation [8]. Through exquisite experimental design, the difference between the compatible and incompatible response time is used as an index for the link between the concepts and acts as a surrogate to expose the real attitude of the experiment participants toward the experimental subject [9]. In the course of the experiment, the purpose of experimental organizer is unknown to the participants, which thus effectively prevents the experiment participants from revising the results [10]. Compared with the other attitude test method, IAT is more efficient. Therefore, the following ten years witnessed a rapid development of IAT. It has then been widely adopted in many fields such as consuming forecast and even presidential election estimates [11,12].

However, there are still some limitations with the IAT method. For instance, the IAT experimental method is heavily dependent on the competition between the experimental subjects during the experiment. Therefore, in terms of experimental subjects, IAT is only suitable for the comparison between different types of subjects or different preferences. However, in this research, it is difficult to find a subject in apparent contrast with residents' attitude towards recycled water reuse. It is necessary, therefore, to find a mature variant that adapts to a single variable implicit test on the basis of the IAT research method. In recent years, some scholars have developed a number of implicit measurement schemes for single subjects on the basis of the classical IAT research program, such as the Single Category Implicit Association Test (SC-IAT), Single Target Implicit Association Test (ST-IAT), Extrinsic Affective Simon Task (EAST), and the Go/No-go Association Task (GNAT) [13-17]. By comparing the four implicit association test methods above for a single subject, we can find that the SC-IAT method assesses the degree to which pairing a single other category with another category dimension facilitates categorization of stimuli [18], and achieves a similar level with the classical IAT in terms of internal consistency, and the operation of the former is simpler. Therefore, it has apparent advantages over the other three IAT test programs.

\subsection{Research Hypotheses}

Compared with explicit attitude, the data on residents' ACC of recycled water obtained through IAT may be much closer to the real attitude. Then, to verify whether the residents will show a negative implicit attitude towards recycled water due to their Spiritual Contagion, Hypothesis 1 is put forward. 
Hypothesis 1. The residents hold a negative implicit attitude towards recycled water from sewage.

Owing to the environmentally friendly and public benefit features of recycled water reuse, as the residents express their attitude toward it, they would likely show more positive explicit attitudes for the sake of face-saving and reputation. Therefore, Hypothesis 2 is put forward.

Hypothesis 2. The residents' apparent explicit attitude towards recycled water reuse is significantly more positive than their implicit attitude.

\section{Experimental Design}

A total of 101 people were invited to participate in IAT in a computer room. The experiment was divided into two parts, the baseline group experiment and the control group experiment. The former aims to obtain the implicit attitude closer to the real attitude of the participants, and the latter attempts to stimulate the participants correspondingly by simulating the action principles of various policies. The ultimate purpose of the control group experiment is to measure the influence of different policies on the participants' implicit attitude towards recycled water reuse so as to verify the guiding effect of environmental protection motivating policy, guiding policy and knowledge popularization policy on residents' recycled water reuse.

\subsection{The Basic Information of the Experiment}

Experiment time: The experiment was conducted from 26 May to 22 June 2016, during which the participants were invited to participate in the implicit association test while not being uninterrupted.

Participants: 101 residents of Xi'an city, who had never participated in the IAT, were invited to participate in the experiment (93 sets of valid data were obtained in the end)_for details, see Table 1. The experiment participants are all right-handed, with normal sight or normal in sight after correction, without extreme emotion in the experiment.

Table 1. Description of subjects for experimental sample.

\begin{tabular}{ccc}
\hline Variables & Total Samples (Person) & Valid Samples (Person) \\
\hline Age (years old) & 51 & 45 \\
$(20,30]$ & 40 & 38 \\
$(30,40]$ & 10 & 10 \\
Above 40 & & \\
Gender & 40 & 37 \\
Male & 61 & 56 \\
Female & & 5 \\
\hline Educational background & 5 & 45 \\
Below bachelor & 51 & 43 \\
Bachelor & 45 & \\
Master's and above & &
\end{tabular}

Preparation of the experiment: the experiment participants are selected in advance to enter the computer room in groups of four. They are asked first to read the informing agreement to make sure they participate in the experiment voluntarily under the condition of knowing the purpose of the experiment. The left-handed participants or participants with extreme emotions are excluded.

\subsection{Introduction to the Experimental Process}

During this phase of the experiment, the participants are invited to complete the SC-IAT response task on recycled water with a computer pre-installed with the E-prime 2.0 application (version, Manufacturer, City US State abbrev. if applicable, Country). After it, they are then asked to answer a 
questionnaire including questions on explicit attitude test and behavior disposition. The explicit test is just after the implicit test to avoid the influence of explicit test on implicit attitude [19].

The implicit attitude of recycled water reuse of SC-IAT test participants was adopted. The SC-IAT test covers two parts and all of the participants in the experiment follow the same test procedure and sequence to take the implicit test. Each part of the experiment can be divided into the first 24 rehearsal groups and follow 48 formal experimental groups. In the first part, "recycled water" and "positive" are put in one category, represented by the key "F". The "Negative" is in the other category, which is represented by the key "J". Different types of responding words are presented in a random order, but the corresponding stimulus of "positive word", "negative word" and "recycled water" remain a presentation frequency of 7:10:7. Therefore, the probability of the right answer to be " $\mathrm{F}$ " and "J" are, respectively, $58 \%$ and $42 \%$. In the second part, "positive" itself is in a category, represented by the key "F". "Recycled water" and "negative" are classified as the other category, represented by the key "J". The presentation frequency of "positive word", "negative word" and "recycled water" is 10:7:7, in a random sequence. In the right answers of this part of the experiment, the probability of " $\mathrm{F}$ " and " $\mathrm{J}$ " is $42 \%$ and $58 \%$, respectively. The experimental process is shown in Table 2.

Table 2. Implicit test process of recycled water.

\begin{tabular}{ccccc}
\hline & \multicolumn{4}{c}{ Recycled Water Single Category-Implicit Association Test (SC-IAT) } \\
\hline Experiment Parts & Experiment No. & Group Category & Key “F” Response & Key “J” Response \\
\hline Baseline group & 24 & Test group & $\begin{array}{c}\text { Positive words }+ \\
\text { recycled water pictures }\end{array}$ & Negative words \\
\cline { 2 - 5 } Control group & 48 & Experiment group & $\begin{array}{c}\text { Positive words }+ \\
\text { recycled water pictures }\end{array}$ & Negative words \\
\cline { 2 - 5 } & 24 & Test group & Positive words & $\begin{array}{c}\text { Negative words }+ \\
\text { recycled water pictures }\end{array}$ \\
\hline
\end{tabular}

Before each group of experiments, there will be some reminding phrases to introduce experiment rules and requirements of the next stage of the experiment. The attribute words include "positive" and "negative" ones. The stimulus is "recycled water". The word set of each attribute word consists of 19 two-character words. Positive words include: high-quality, be keen on, safe, healthy, excellent, good, comfortable, happy, joyful, clean, spotless, worry-free, clear, environment friendly, beneficial, agree, trust, useful, glad; Negative words: poor quality, nasty, dangerous, sick, terrible, bad, unhappy, sad, painful, dirty, foul-smelling, depressing, muddy, polluted, harmful, object, doubt, useless, and grieved. The pictures of the stimulus consist of seven pictures representing the production and the use of recycled water.

In terms of experimental interface design, on the top left and right corner, the reminding words of the key "F" and "J" are displayed. The stimulus will be shown in the center of the screen. The stimulating pictures will always appear in the center of the screen until the experiment participants responded by clicking either the letter " $\mathrm{F}$ " or " $\mathrm{J}$ ". In the rehearsal phase of each experiment, when the participants press the keys to respond, in the center of the screen, there will occur feedback of 150 milliseconds to show right or wrong. When the response is right, there will be a green " $\mathrm{O}$ "; otherwise, there will be a red " $X$ ".

The explicit attitude of the participants towards recycled water is tested by the explicit questionnaire. In this session, the experiment participants are asked to answer the questions of semantic differences, mark the attitude and evaluate to what extent they support recycled water [20]. Likert 7-scale is used in semantic difference test. " -3 " refers to the negative pole, while " 3 " the positive pole. This section is comprised five questions. The attribute words representing the left and right poles of the scale are five groups of common antonyms: bad-good, ugly-beautiful, unhappy-happy, 
opposed-approved, hate-like. The experiment participants need to check the scoring items of different distances from the two poles. When the scoring item is closer to a certain pole, the attitude towards the recycled water is closer to the corresponding attribute words of the pole. When the participants choose " 0 ", their attitude towards recycled water is neutral. The five questions are all about the participants' attitude towards recycled water reuse $(\alpha=0.871)$, so the score of the semantic difference should be the average score of the five questions. The scoring questions about the participants' attitude required the participants to assess whether recycled water is positive or negative, the score ranges from 0 (extreme negative) to 100 (extreme positive). To get the supporting degree, participants are asked to score on a 6-scale to express their supporting degree of the statement "I'm very supportive to recycled water reuse". The higher the scoring is, the higher the supporting degree will be. All of the questions of the three types are about the participants' explicit attitude towards recycled water ( $\alpha=0.845)$, so the final score of the experiment participants' explicit test can be calculated as the mean after the three types of test answers are unified in dimension.

\section{Empirical Analysis}

\subsection{Verification of Residents' Spiritual Contagion of Recycled Water Reuse}

To overcome the shortcomings of the data conclusion obtained from the questionnaire, which is easily influenced by the mainstream value and subjective factors, this part of the study introduces the IAT method used to measure the real attitudes of the participants in the social psychology research field. This attempts to verify whether the residents have Spiritual Contagion about recycled water reuse from the same perspective of their implicit attitude.

\subsubsection{Research Objectives}

Through the experimental method of IAT, this research aims to obtain findings that align with the residents' real attitude about recycled water to verify whether there is Spiritual Contagion about recycled water reuse.

\subsubsection{Data Analysis and Hypothesis Testing}

In consolidating data, we gave an additional $400 \mathrm{~ms}$ to participants who answered incorrectly. Experiment data with error rate greater than $20 \%$ is removed. In order to avoid influence from extreme outliers, the data with response times of less than 350 milliseconds and more than 2000 milliseconds are also removed [13]. After the completion of the above data processing process, the first thing to do is to take the average of the response time data, and then calculate the different experiment participants' $\mathrm{D}$ value by the $\mathrm{D}$-value method [19]. That is, to average the difference of the mean difference of the response times of different sections of the experiment. The result is taken as reference for the following implicit attitude analysis. The specific process should be subtracting the mean response time of the control group in formal experiments from that of the baseline group in formal experiments. Therefore, in the SC-IAT experiment, a negative D value indicates that the participants' attitudes towards recycled water reuse is positive and vice versa. At the same time, the greater the absolute value of the $D$ value, the more obvious the deviation of the attitude. The final data statistics are shown in Table 3.

Table 3. Experimental data summarization of the baseline group.

\begin{tabular}{ccc}
\hline Groups & Mean Value & Standard Deviation \\
\hline "Recycled water + positive" group average response time (P) & 814.579 & 145.947 \\
"Recycled water" group average response time (N) & 760.184 & 147.186 \\
P-N value & 54.395 & 55.126 \\
\hline
\end{tabular}

From Table 3, it is found that the $D$ value is positive $(D=54.395)$, representing the negative implicit attitude, and there is a significant difference between the average response time before and 
after $(t(93)=9.516, p<0.001)$. Thus, we can know that the residents' implicit attitude is negative, and Hypothesis 1 is tenable.

\subsection{The Causes for the "Best Game No One Played" Phenomenon of Recycled Water}

In the current promotion of recycled water in China, there is a "best game no one played" phenomenon. To be specific, residents often verbally show that recycled water is beneficial, but are still unwilling to choose to use it in their own lives. The same phenomenon also exists in the promotion of recycled water in the whole society. The study of residents' prejudice against recycled water reuse will explain this phenomenon to some extent. That is, residents are unwilling to accept recycled water reuse because it is produced from polluted water. Though the pollution can be removed through sewage treatment, the treatment technology has no way to remove the prejudice deeper in residents' minds [21-23]. Because the water resources and environmentally friendly features of recycled water are connected with those positive concepts of environment protection and public benefit, the attitude towards recycled water reuse naturally is more connected with a person's reputation and face [24]. Therefore, the explicit attitude towards recycled water obtained through self-reporting will probably be affected by the mainstream value of the society. That is why a more positive attitude will be expressed. Based on the above two theories, first, it can be speculated that the prejudice will have a reverse effect on residents' real attitude expression. Second, it can be speculated that, when answering the questionnaire, due to reputation-maintaining and face-saving, residents would like to show more positive explicit attitudes towards recycled water. The deviation between the real attitude and the explicit attitude learnt from the questionnaire may be the real cause of the phenomenon.

\subsubsection{Research Objectives}

By comparing residents' implicit attitude with their explicit attitude, the differences between the two types of attitude are shown. Then, the phenomenon of "best game no one played" of recycled water reuse promotion in China is explained.

\subsubsection{Data Analysis and Hypothesis Testing}

In the summarizing of the explicit data, it is found that the mean value gets to 79.284 (SD =9.511), which is much higher than 50 points. It shows that the participants have a positive preference for recycled water. Comparing it with the implicit attitude obtained before, we find that the explicit attitude is more positive than implicit attitude, so Hypothesis 2 is also tenable.

\section{Results and Implications}

Residents hold a negative implicit attitude towards recycled water from sewage. Based on the experimental method of IAT, this study measures residents' implicit attitude towards reclaimed water. It is found that residents hold a negative implicit attitude to recycled water reuse, which has verified residents' prejudice against recycled water reuse. Meanwhile, it also reminds us of finding ways to remove residents' prejudice at the same time as removing the pollutants in the sewage. It can be seen that the sole construction of recycled water reuse infrastructure without educating and guiding the residents may simply bring about additional supply instead of the revitalization of the recycled water industry.

In contrast to implicit attitude, experiment participants may reveal more positive explicit attitudes to recycled water. Due to the environmental properties of recycled water reuse, the attitude towards recycled water reuse will be connected with one's environmental awareness, dedication awareness and even moral level. The residents with negative feedback on the reuse of recycled water may hide their real attitudes towards recycled water due to factors such as reputation maintaining or face-saving but give answers that are more in line with the expectations of the community. This behavior disposition finds its evidence in a follow-up interview of the participants. A participant who is a harsh grader (whose scoring is very close to the neutralizing attitude) in the explicit 
attitude test of recycled water reuse said, "I marked down, and feel that I have no environmental awareness". At the same time, since it is difficult for participants to hide their real thoughts in IAT, the implicit attitude obtained in it would be much closer to the real attitude of the residents. Therefore, the differences between implicit and explicit attitudes show the deviation between residents' real attitude and the explicit attitude learnt from the questionnaire survey. This may be one of the real causes of the "best game no one played" phenomenon. This can also inspire us in believing that the real attitude of the residents to the reuse of recycled water is not as positive as they report. To improve residents' real attitude towards recycled water reuse, perhaps, is more effective than the surface support of recycled water reuse.

Acknowledgments: All sources of funding of the study should be disclosed. Please clearly indicate grants that you have received in support of your research work. Clearly state if you received funds for covering the costs to publish in open access.

Author Contributions: Hanliang Fu designed the research topic and drafted the manuscript; Xiaojun Liu shared efforts in data analysis and provided suggestions to revise the paper.

Conflicts of Interest: The authors declare no conflict of interest.

\section{References}

1. Bogardi, J.J.; Dudgeon, D.; Lawford, R.; Flinkerbusch, E.; Meyn, A.; Pahl-Wostl, C.; Vielhauer, K.; Vörösmarty, C. Water security for a planet under pressure: Interconnected challenges of a changing world call for sustainable solutions. Curr. Opin. Environ. Sustain. 2012, 4, 35-43. [CrossRef]

2. Huertas, E.; Salgot, M.; Hollender, J.; Weber, S.; Dott, W.; Khan, S.; Schäfer, A.; Messalem, R.; Bis, B.; Aharoni, A.; Chikurel, H. Key objectives for water reuse concepts. Desalination 2008, 218, 120-131. [CrossRef]

3. Dolnicar, S.; Hurlimann, A.; Grün, B. What affects public acceptance of recycled and desalinated water? Water Res. 2011, 45, 933-943. [CrossRef] [PubMed]

4. Chen, Z.; Huu, H.N.; Guo, W.S. A Critical review on the end uses of recycled water. Crit. Rev. Environ. Sci. Technol. 2013, 43, 1446-1516. [CrossRef]

5. Li, Y.; Qu, X.; Sun, R. Health Effects Associated with Wastewater Treatment, Reuse, and Disposal. Water Environ. Res. 2015, 44, 1954-1977. [CrossRef] [PubMed]

6. Callaghan, P.; Moloney, G.; Blair, D. Contagion in the representational field of water recycling: Informing new environment practice through social representation theory. J. Community Appl. Soc. Psychol. 2012, 22, 20-37. [CrossRef]

7. Rozin, P.; Haddad, B.; Nemeroff, C.; Slovic, P.; Baron, J. Psychological aspects of the rejection of recycled water: Contamination, purification and disgust. Judgm. Decis. Mak. 2015, 10, 50-63.

8. Greenwald, A.G.; Mcghee, D.E.; Schwartz, J.L.K. Measuring Individual Differences in Implicit Cognition: The Implicit Association Test. J. Personal. Soc. Psychol. 1998, 74, 1464-1480. [CrossRef]

9. Yang, Z.; Liu, Y.; Yu, Z.; Cai, H. Applications of Implicit Association Test. Adv. Psychol. Sci. 2015, 23, $1966-1980$. [CrossRef]

10. Houwer, J.D. A Structural and Process Analysis of the Implicit Association Test. J. Exp. Soc. Psychol. 2001, 37, 443-451. [CrossRef]

11. Ratliff, K.A.; Swinkels, B.A.P.; Klerx, K.; Nosek, B.A. Does One Bad Apple (Juice) Spoil the Bunch? Implicit Attitudes toward One Product Transfer to Other Products by the Same Brand. Psychol. Marking 2012, 29, 531-540. [CrossRef]

12. Ratliff, K.A.; Howell, J.L. Implicit Prototypes Predict Risky Sun Behavior. Health Psychology Official. J. Div. Health Psychol. Am. Psychol. Assoc. 2015, 34, 231-242.

13. Karpinski, A.; Steinman, R.B. The Single Category Implicit Association Test as a measure of implicit social cognition. J. Personal. Soc. Psychol. 2006, 91, 16-32. [CrossRef] [PubMed]

14. Wigboldus, D.H.J.; Holland, R.W.; Brown, A.S.; Gray, N.S.; Snowden, R.J. A Single target implicit associations. Unpublished manuscript, 2017.

15. Houwer, J.D. The Extrinsic Affective Simon Task. Exp. Psychol. 2003, 50, 77-85. [CrossRef] [PubMed]

16. Nosek, B.A.; Banaji, M.R. The Go/No-go Association Task. Soc. Cogn. 2001, 19, 625-664. [CrossRef] 
17. Nosek, B.A.; Greenwald, A.G.; Banaji, M.R. Understanding and using the Implicit Association Test: II. Method variables and construct validity. Personal. Soc. Psychol. Bull. 2005, 31, 166-180. [CrossRef] [PubMed]

18. Carnevale, J.J.; Fujita, K.; Han, H.A.; Amit, E. Immersion Versus Transcendence: How Pictures and Words Impact Evaluative Associations Assessed by the Implicit Association Test. Soc. Psychol. Personal. Sci. 2015, 6, 92-100. [CrossRef]

19. Greenwald, A.G.; Nosek, B.A.; Banaji, M.R. Understanding and using the implicit association test: I. An improved scoring algorithm. J. Personal. Soc. Psychol. 2003, 85, 197-216. [CrossRef]

20. Liu, M.; Wang, Y. Data collection mode effect on feeling thermometer questions: A comparison of face-to-face and Web surveys. Comput. Hum. Behav. 2015, 48, 212-218. [CrossRef]

21. Hurlimann, A.; Dolnicar, S. Public acceptance and perceptions of alternative water sources: A comparative study in nine locations. Int. J. Water Resour. Dev. 2016, 32, 1-24. [CrossRef]

22. Fu, H.; Liu, X. A Study on the Impact of Environmental Education on Individuals' Behaviors Concerning Recycled Water Reuse. EURASIA J. Math. Sci. Technol. Educ. 2017, 13, 6715-6724. [CrossRef]

23. Dolnicar, S.; Hurlimann, A. Water alternatives-who and what influences public acceptance? J. Public Aff. 2010, 11, 49-59. [CrossRef]

24. Hu, H.; Lin, J.; Qin, Y.; Sun, J. Strategies for new product diffusion: Whom and how to taget? J. Bus. Res. 2018, 83, 111-119. [CrossRef]

(C) 2017 by the authors. Licensee MDPI, Basel, Switzerland. This article is an open access article distributed under the terms and conditions of the Creative Commons Attribution (CC BY) license (http:/ / creativecommons.org/licenses/by/4.0/). 